\title{
Пищевая биотехномогия
}

\author{
УДК637.5.04/.07 \\ DOI: http://dx.doi.org/10.20914/2310-1202-2016-1-89-95
}

Профессор Л.В. Антипова, аспирант М.В. Горбунков

(Воронеж. гос. ун-т инж. технол.) кафедра технологии продуктов животного происхождения. тел. (473)255-27-65

E-mail: antipova.L54@yandex.ru

Professor L.V. Antipova, graduate M.V. Gorbunkov

(Voronezh state university of engineering technologies) Department technology products of animal origin. phone (473)255-27-65

E-mail: antipova.L54@yandex.ru

\section{Физико-химические и биокаталитические свойства протеолитического комплекса препарата «Протепсин»}

\section{Physical-chemical and biocatalytic properties of a proteolytic complex of the preparation "Protepsin"}

Peферат. Ферментные технологии прочно вошли в практическую деятельность человека, объем мирового рынка постоянно растет и обновляется. Однако отечественное производство ферментных препаратов весьма отстает от мирового уровня, что во многом связано с недостаточной научно-технической базой для широкого распространения технологий в крупномасштабном производстве. В то же время появились российские производители ферментных препаратов из животных тканей и органов для обработки сырья животного происхождения, по прогнозам, представляющие интерес в рациональном использовании ресурсов животного происхождения. В статье приведены данные по исследованию свойств ферментного препарата «Протепсин» и оценке перспективности применения в обработке сырья животного происхождения. Ферментный препарат «Протепсин», производимый в условиях $3 А О$ «Завод эндокринных ферментов» (п. Ржавки, Московская область) проявляет активность при действии на белки мяса, включая белки упрочненной структуры, обладает молокосвертывающим эффектом, активен в области $\mathrm{pH} 4,0-6,0$ и температуре $20-45^{\circ} \mathrm{C}$. Белковый комплекс включает 4 фракции, 2 из которых обладают общей протеолитической активностью. Одна из них проявляет общую протеолитическую и молокосвертывающую активность. Ферменты отличаются аминокислотным набором и молекулярной массой. Методом дискового электрофореза определен молекулярно-массовый состав «Протепсина». Показаны условия инактивации препарата, гарантирующие его безопасность в технологии производства пищевых продуктов, так как активные протеолитические ферменты в процессе пищеварения могут вызывать нарушения целостности тканей и соответствующие заболевания. Таким образом, комплексно обоснованы и подобраны условия использования перспективного протеолитического препарата в технологии широкого спектра продуктов питания животного происхождения.

Summary: Enzymatic technologies were included strongly into practical activities of the person, the volume of the world market constantly grows and is updated. However the domestic production of enzymatic preparations very lags behind world level that is in many respects connected with insufficient scientific and technical base for a wide circulation of technologies in large-scale production. At the same time there were Russian producers of enzymatic preparations from animal fabrics and bodies for processing of raw materials of an animal origin, according to forecasts, of interest in rational use of resources of an animal origin. In article data on research of properties of the enzymatic preparation "Protepsin" and an assessment of prospects of application are provided in processing of raw materials of an animal origin. The enzymatic preparation "Protepsin" made in the conditions of JSC Plant of Endocrine Enzymes (Rzhavki, Moscow region) activity at action on proteins of meat shows, including the strengthened structure, has milk-clotting effect, is active in the field of $\mathrm{pH}$ 4,0-6,0 and temperature 20-45zs. The proteinaceous complex includes 4 fractions, 2 from which possess the general proteolytic activity. One of them shows the general proteolytic and milk-clotting activity. Enzymes differ in an amino-acid set and molecular weight. The method of a disk electrophoresis determined molecular-mass structure of "Protepsin". The preparation inactivation conditions guaranteeing its safety in the production technology of foodstuff as active proteolytic enzymes in the course of digestion can cause violations of integrity of fabrics and corresponding diseases are shown. Thus, conditions of use of a perspective proteolytic preparation in technology of a wide range of food of an animal origin are in a complex proved and picked up.

Ключевые слова: ферментные технологии, сырье животного происхождения, протеолитический комплекс, молокосвертывающий эффект, идентификация ферментов.

Keywords: enzymatic technologies, raw materials of an animal origin, proteolytic complex, milk-clotting effect, identification of enzymes.

Для цитирования

Антипова Л.В., Горбунков М.В. Физико-химические и биокаталитические свойства протеолитического комплекса препарата «Протепсин» // Вестник Воронежского государственного университета инженерных технологий. 2016. №1. С. 89-95. doi:10.20914/2310-1202-2016-1-89-95.
(С Антипова Л.В., Горбунков М.В., 2016

For cite

Antipova L.V., Gorbunkov M.B. Physical-chemical and biocatalytic properties of a proteolytic complex of the preparation "Protepsin". Vestnik voronezhskogo gosudarstvennogo universiteta inzhenernyh tekhnologij [Proceedings of the Voronezh state university of engineering technologies] 2016, no. 1, pp. 89-95. (In Russ.). doi: 10.20914/ 2310-1202-2016-1-89-95. 
Несмотря на бурное развитие биотехнологий в мире, отечественное производство ферментных препаратов остается недостаточно развитым. Вместе с тем, рынок ферментных препаратов пополнился за счет технологий переработки животных органов и тканей для получения протеаз и их применения при производстве инновационных продуктов животного происхождения, социальное и экономическое значение которых трудно переоценить. Ферментные технологии позволят увеличить выход полезной продукции с единицы перерабатываемого сырья, снизить себестоимость, улучшить качество, повысить пищевую и биологическую ценность, рационально и максимально использовать ресурсы для производства пищевого сырья и продуктов, создать гибкий ассортимент, ориентированный на социальные и физиологические группы населения с высокими потребительскими свойствами, в том числе, обогащенных биологически активными веществами, а также новые источники и формы пищи, обеспечить продовольственную безопасность страны [1-4].

Среди новинок выступает ферментный препарат «Протепсин», вырабатываемый в условиях ЗАО «Завод эндокринных ферментов» (п. Ржавки, Московская область) по ТУ 9219-005-427-89-257. По данным производителя и авторов (Антипова Л.В., Бибишев Р.А.,
Косенко И.С.) ферментный препарат «Протепсин» - порошок светло-серого цвета, маркируется по уровню активности: 50, 100 и 150 ед/г. Его рабочая активность проявляется в диапазоне температур $20-45{ }^{\circ} \mathrm{C}$ при оптимуме в мясных системах $40{ }^{\circ} \mathrm{C}$. Полная инактивация ферментного комплекса отмечается при $70^{\circ} \mathrm{C}$ в течение 15 минут. Рекомендуемая норма при обработке мяса и мясных продуктов в диапазоне $\mathrm{pH}$ 4,5-6,0 составляет 0,01-0,05 \% к массе сырья с учетом уровня стандартной активности, вида и состояния сырья, а также особенностей технологии применения.

Препарат апробирован и зарекомендовал себя для ускорения процессов созревания и тендеризации мяса. Препарат - синергист внутриклеточных ферментов мышечной ткани, однако обладает более широким спектром воздействия на белки мяса.

Общий химический состав препарата, определенный традиционными методами, представлен (масс, \%): влага - 10,94; белок 87,52 ; жир $-0,61$; зола $-0,93$.

При проведении сравнительных исследований был установлен аминокислотный состав препарата в сравнении с известными аналогами (таблица 1) с использованием аминоанализатора АAА-881 (Чехия), в соответствии с инструкцией к прибору.

Т а б л и ц а 1

Аминокислотный состав ферментов кислых протеиназ

\begin{tabular}{|c|c|c|c|}
\hline \multirow{2}{*}{ Аминокислоты } & \multicolumn{3}{|c|}{ Содержание аминокислот, г/100 г белка } \\
\cline { 2 - 4 } & Микробный препарат & Пепсин животных & «Протепсин» \\
\hline 1 & 2 & 3 & 4 \\
\hline Аланин & 6,8 & - & 3,0 \\
\hline Аргинин & 1,1 & 1,0 & 0,87 \\
\hline Аспарагиновая кислота & 16,2 & 16,0 & 17,2 \\
\hline Цистин & - & 1,6 & 1,3 \\
\hline Глютаминовая кислота & 9,7 & 11,9 & 5,9 \\
\hline Глицин & 6,8 & 6,4 & 0,98 \\
\hline Гистидин & 1,1 & 0,9 & 5,4 \\
\hline Изолейцин & 3,6 & 10,8 & 8,8 \\
\hline Лейцин & 10,2 & 10,4 & 1,14 \\
\hline Лизин & 0,5 & 0,9 & 1,4 \\
\hline Метионин & 2,0 & 1,7 & 7,14 \\
\hline Фенилаланин & 11,4 & 6,4 & 1,13 \\
\hline Пролин & 1,7 & 5,0 & 9,9 \\
\hline Серин & 5,0 & 12,2 & 8,9 \\
\hline Треонин & 10,9 & 9,6 & 5,4 \\
\hline Тирозин & 6,6 & 8,5 & 5,8 \\
\hline Валин & 14,2 & 7,1 & 1,3 \\
\hline Триптофан & 1,3 & 2,4 & \\
\hline
\end{tabular}


Как видно из данных таблицы 1 , в состав белков-ферментов входит полный перечень протеиногенных аминокислот. Несмотря на очевидно общие черты, ферменты отличаются по содержанию отдельных аминокислот, что может быть связано как со структурными особенностями, так и со степенью чистоты исследуемых ферментов в препарате. Заметно, что приведенные в таблице ферменты на 50 и более процентов состоят из гидрофобных аминокислот, что предполагает значительную роль гидрофобных взаимодействий в стабилизации пространственной структуры. При этом в составе преобладают аспарагиновая и глютаминовая аминокислоты, сумма которых составляет 25,9$27,7 \%$, что объясняет «кислую» природу ферментов, активных в области низких значений pH. В препарате «Протепсин» содержится незначительное количество гистидина, но более выражен лизин по сравнению с аналогами. Исходя из выше изложенного можно предполагать, что ферменты наряду со структурными имеют и функциональные особенности.

Данные обстоятельства диктуют необходимость углубленного изучения компонентного состава протеолитического комплекса, физико-химических свойств и структурных особенностей входящих в него ферментов. Исследования представляют интерес еще и потому что «Протепсин» обнаруживает молокосвертывающую активность наряду с общей протеолитической, что весьма важно в оценке перспектив и расширении области применения препарата в обработке не только мясного, но и молочного сырья.

Препарат подвергали электрофоретическим исследованиям и хроматографии для определения фракционного состава белков и идентификации протеолитических фракций, в том числе обладающих молокосвертывающей активностью. Предварительно подготовленный к анализу препарат подвергали электрофоретическому разделению методом дискового электрофореза (рисунок 1) в соответствии с инструкцией к прибору.

Как видно на рисунке 1 (a), белковый комплекс препарата представлен четырьмя белковыми фракциями, отличающимися подвижностью в среде ПААГ, а следовательно молекулярной массой и величиной поверхностного заряда.

Идентификацию протеолитических фракций вели в ПААГ с использованием гемоглобина. При этом предварительно подвергнутый электрофоретическому разделению в ПААГ препарат извлекали из трубочки вместе с гелем и обрабатывали в растворе $2 \%$ гемоглобина при $\mathrm{pH} 4,0$ в течение 3 -х часов при комнатной температуре. Затем гель фиксировали в растворе ТХУ и проводили окрашивание белков $[5,6]$. Протеолитические фракции проявлялись в виде прозрачных полос на фоне интенсивно окрашенного гемоглобина в геле. Эксперимент доказывает наличие двух фракций, обладающих общей протеолитической активностью, так как локализованные в геле протеолитические фракции глубоко расщепляют субстрат с образованием низкомолекулярных продуктов, диффундирующих в среду красителя.

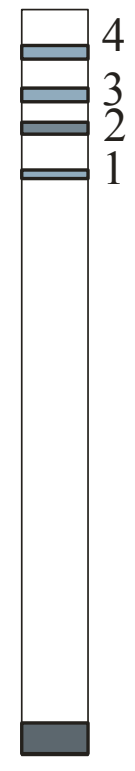

a

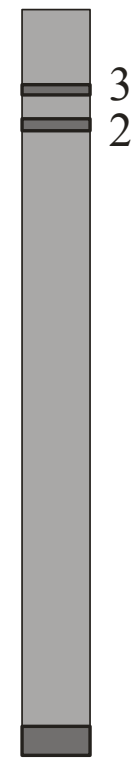

6
Рисунок 1. Исследование протеолитического комплекса «Протепсин» методом дискового электрофореза: а) фракции белков препарата; б) идентификация протеолитических фракций

Второй способ идентификации состоял в том, что предварительно электрофоретически разделенные белковые фракции вырезали в геле в соответствии с пройденным фронтом и помещали в пробирку с дистиллированной водой (в 10 мл), проводили экстракцию в течение 3 -х часов и в экстрактах определяли содержание белка, общую протеолитическую и молокосвертывающую активности. Экстракция белковых полос, вырезанных из геля, позволила идентифицировать две протеолитические фракции, названные нами протеиназа I и II соответственно, но лишь протеиназа II обладала молокосвертывающей активностью, которая определялась на обезжиренном молоке при $\mathrm{pH} 6,5$ и температуре $35^{\circ} \mathrm{C}$ по времени свертывания (рисунок 2). 


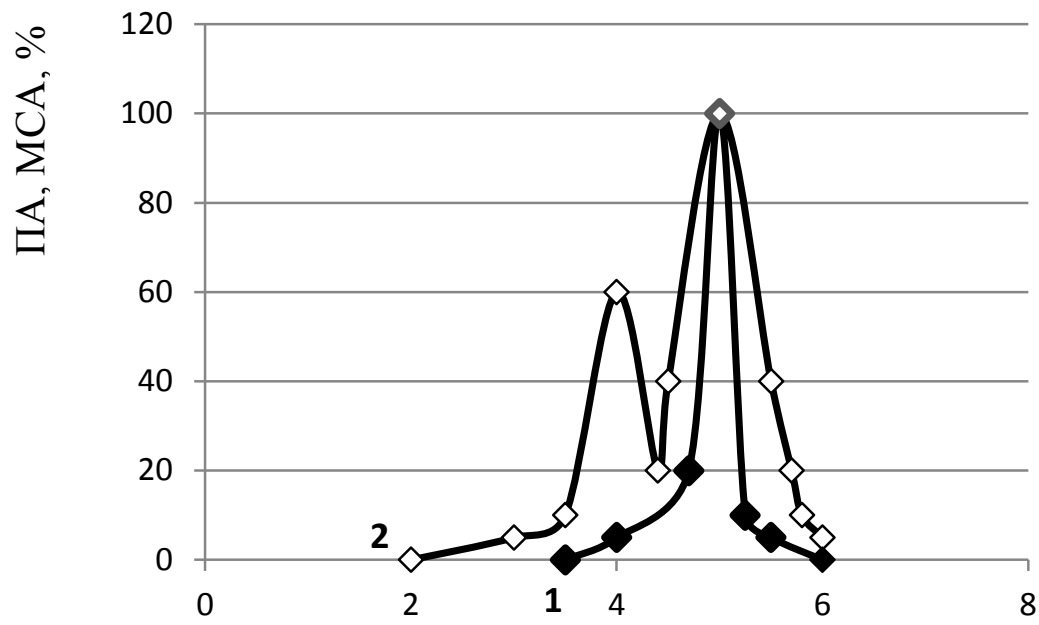

№ фракций

Рисунок 2. Идентификация протеолитических фракций препарата «Протепсин»: -৮-(1) - MCA, 一 - (2) - ПА

Судя по интенсивности протеолиза гемоглобина в геле, а также различию фронтов при электрофоретическом разделении фракций, протеолитические ферменты отличаются функционально, в частности, они по разному действуют на казеин молока, что указывает на отличия в субстратной специфичности.

Аналогичные результаты были получены при фракционировании белковых фракций препарата на ДЭАЭ - целлюлозе и сефадексе $\mathrm{G}$ - 100, последний использовался для количественного накопления ферментов и дальнейших исследований.

Основными факторами управления биохимическими процессами в пищевом сырье и продуктах выступают рН и температура, которые должны обеспечивать максимальную активность и полную инактивацию в конечном продукте. В ходе экспериментальных исследований установлено влияние этих факторов на протеолитическую активность ферментов препарата в модельном опыте: к 2 мл $2 \%$ раствора стандартного субстрата добавляли по 2 мл растворов гомогенных фракций протеолитического комплекса с содержанием белка 600 мкг/мл. Гидролиз вели при температуре $35^{\circ} \mathrm{C}$ в течение 30 мин. Результаты определения активности в каждой пробе представлены в виде графической зависимости $\mathrm{A}=\mathrm{f}(\mathrm{pH})$ (рисунок 3 ).

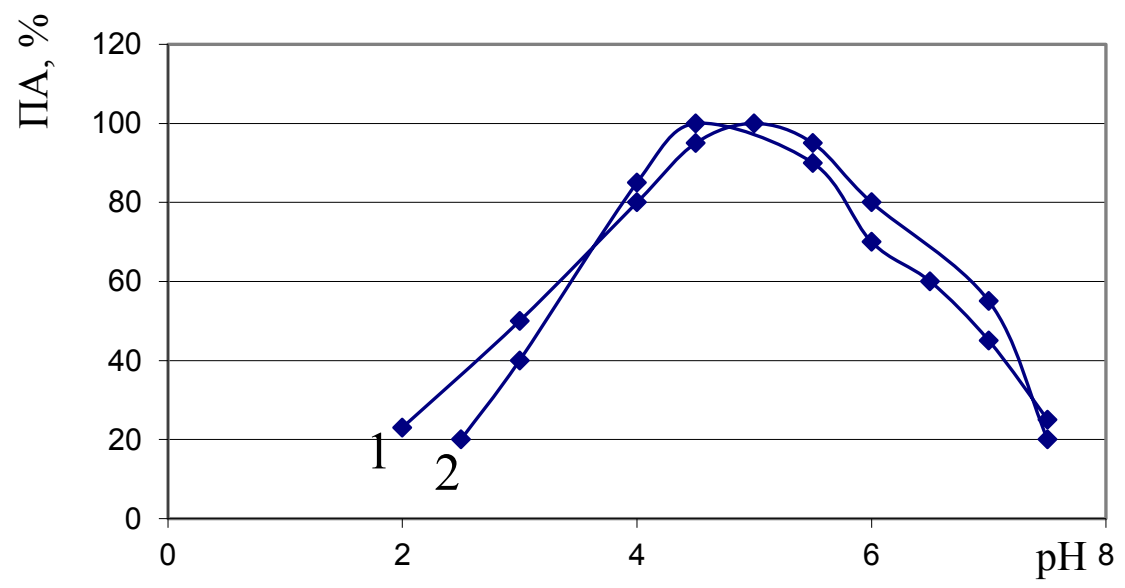

Рисунок. 3. Влияние $\mathrm{pH}$ на активность ферментов протеолитического комплекса препарата «Протепсин»: 1 - протеиназа II, 2 - протеиназа I 
Ферменты достоверно различаются $\mathrm{pH}-$ оптимумами, при этом протеиназа I имеет максимальное значение активности при рН 4,0-4,5, а протеиназа II - при рН 4,5-5,0.

Аналогичные исследования проводили при воздействии температуры на реакционные смеси. Температуру поддерживали с помощью водяного термостата в диапазоне $20-70{ }^{\circ} \mathrm{C}$. Результаты определения ПА в каждом опыте представлены на рисунке 4.

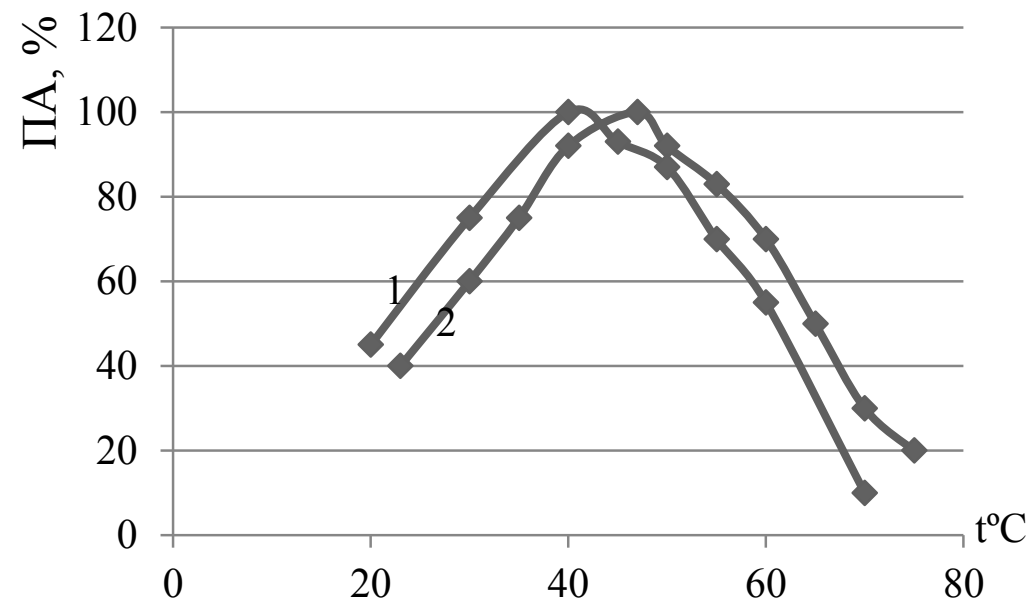

Рисунок. 4. Влияние температуры на активность протеолитических ферментов препарата «Протепсин»: 1 - протеиназа II, 2 - протеиназа I

Как видно на рисунке 4, оба фермента имеют температурный оптимум действия, характерный для ферментов животного происхождения, при этом протеиназа I наиболее активна при температуре $45^{\circ} \mathrm{C}$, а протеиназа II - при $40^{\circ} \mathrm{C}$.

Для ферментных препаратов, работающих в пищевых системах, весьма важна информация о пределах активности и кинетики инактивации под воздействием $\mathrm{pH}$ и температуры, так как активные протеолитические ферменты в процессе пищеварения могут вызывать нарушения целостности тканей и соответственные заболевания.

Инактивация ферментов под действием $\mathrm{H}^{+}$ионов представляет собой результат предварительных ионизационных процессов, глубоко затрагивающих электростатические взаимодействия в белковой молекуле фермента. При этом в конечном счете в каждом элементарном акте инактивации принимают участие только молекула фермента и именно в ней самой происходит изменение специфической конформации, ведущее к разрушению каталитического центра.

Инактивацию можно представить как мономолекулярную реакцию, протекающую по схеме:

$$
\mathrm{E}_{\mathrm{a}}{ }^{\mathrm{K}} \rightarrow \mathrm{E}_{\text {ин }}
$$

где $\mathrm{E}_{\mathrm{a}}$ и $\mathrm{E}_{\text {ин }}$ - активная и инактивированная форма фермента соответственно; к - константа скорости перехода активной формы в инактивированную.
На примере многих ферментов микробного, растительного и животного происхождения показано, что кинетика их инактивации реакция первого порядка. На основании расчетов энергии активации (Ека $)$ и энтропии $\left({ }_{\Delta} \mathrm{S}\right)$ сделали вывод о том, что процесс связан с глубокими изменениями нативной конформации.

Реакция первого порядка описывается уравнением 1 [7]:

$$
\kappa=\frac{2,303}{\tau} * \lg \frac{a}{a-x}
$$

где: $\mathrm{a}$ - исходная концентрация фермента, которая для мономолекулярных реакций первого порядка выражается в г-моль, в мг белка или азота, \%; а - х - концентрация активного фермента в момент времени $(\tau)$.

Учитывая, что активность фермента определяется в строго стандартных условиях, уравнение 1 удобно выразить через активность фермента:

$$
\kappa=\frac{2,303}{\tau} * \lg \frac{[E o]}{[E]}
$$

где: $\left[\mathrm{E}_{\mathrm{o}}\right]$ - исходная активность (во всех опытах $\left.\left[\mathrm{E}_{\mathrm{o}}\right]=100 \%\right)$; [E] - активность фермента в момент времени $(\tau)$; К - константа скорости инактивации (удельная скорость инактивации), характеризующая потерю активности в течение часа $\left(\kappa, ч^{-1}\right)$. Величину $\underline{\mathrm{K}}$ находили как среднюю арифметическую величину из 5-6 повторностей.

Кислотную инактивацию ферментов препарата «Протепсин» изучали в интервале $\mathrm{pH}$ 2,0-7,0 в фосфатно-цитратном буфере с ионной 
силой 0,05 . Во всех случаях использовали одну и ту же концентрацию фермента: 600 мкг/мл для ПА и 3 мкг/мл - для МСА. Среды инкубировали при температуре $30^{\circ} \mathrm{C}$ и через определенные промежутки времени (20-30 минут) определяли ПА и МСА в каждой пробе.

Установлено, что наибольшая стабильность отмечается при рН 4,0-4,5 для протеи- назы I и при рН 4,5-5,0 - протеиназы II. Ферменты значительно теряли активность в слабокислой и около нейтральной средах.

На примере протеиназы II (рисунок 5) видно, что инактивация по ПА и МСА практически совпадает, что говорит о том, что это один и тот же фермент.

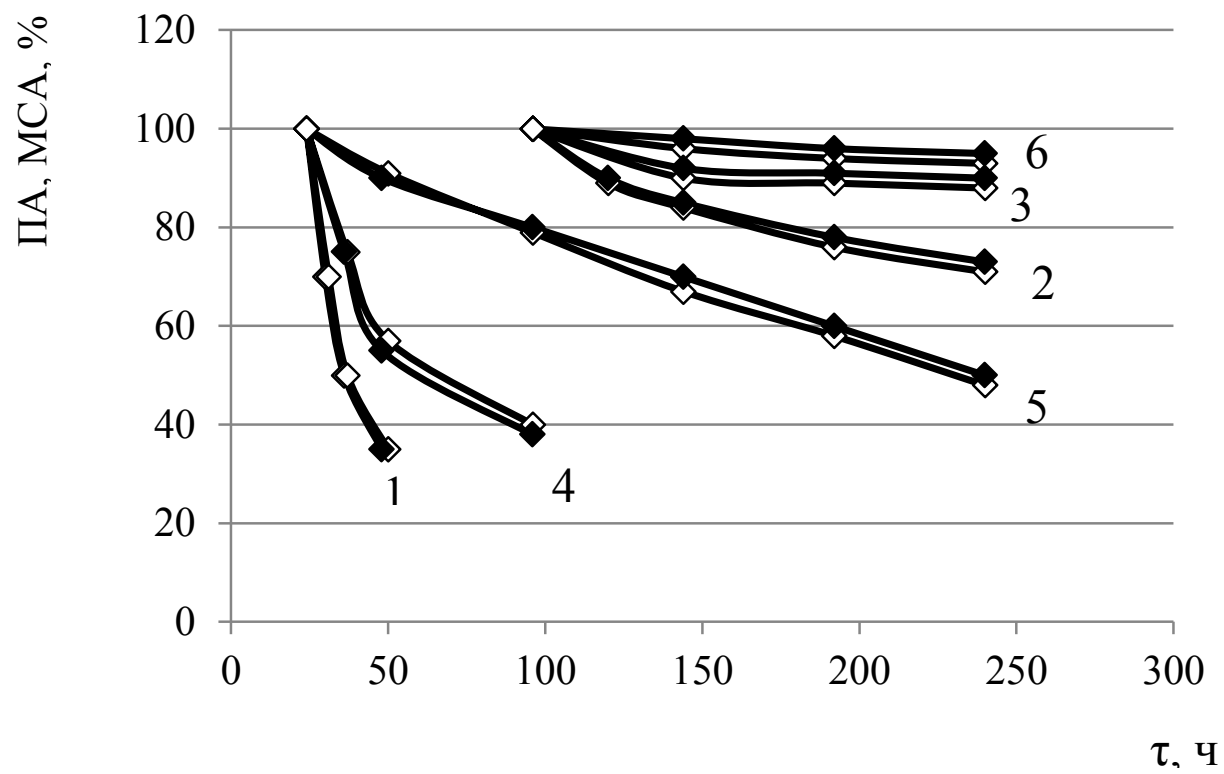

Рисунок 5. Инактивация протеиназы II препарата «Протепсин» в зависимости от времени при температуре $30^{\circ} \mathrm{C}$ :

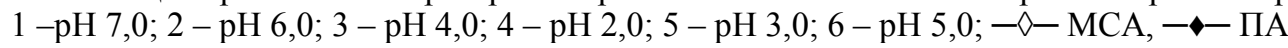

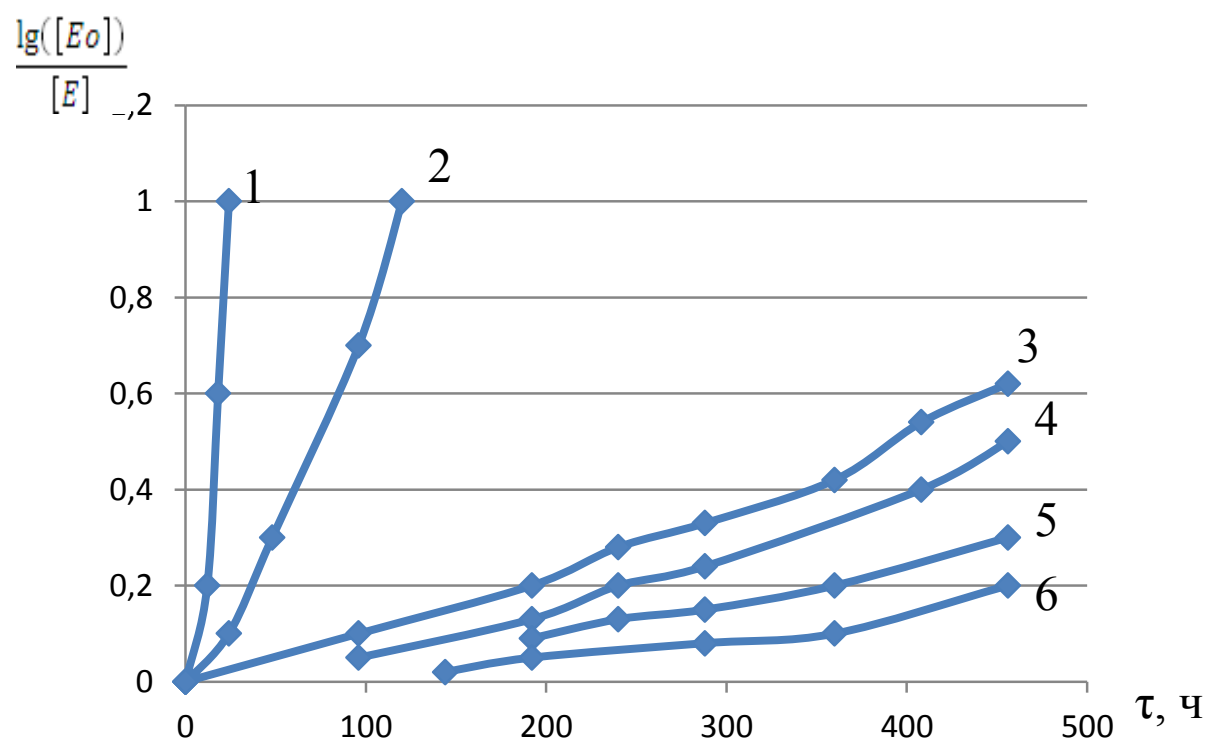

Рисунок 6. Зависимость $\lg \left[\mathrm{E}_{\mathrm{a}}\right] /[\mathrm{E}]$ от $\mathrm{pH}$ протеиназы II; pH: 1 - 7,0; 2 - 6,0; 3 - 4,0; 4 - 2,0; 5 - 3,0; 6 - 5,0

На рисунке 6 видно, что зависимость $1 \mathrm{~g}$ $\left[\mathrm{E}_{\mathrm{a}}\right] /[\mathrm{E}]$ от $\mathrm{pH}$ является характерной для реакции первого порядка. Расчетные данные показывают, что область кислотной инактивации протеиназ препарата «Протепсин» максимально приближен к пепсину животных.

Термическую инактивацию протеиназы II изучали в интервале температур $30-70$ $\mathrm{C}$ в зоне pH 3,0-7,0. Так как температура и концентрация $\mathrm{H}^{+}$- ионов является тесно связанными и не исключающими друг друга факторами интенсивности процесса инактивации, мы предполагали, что термическая инактивация описывается также уравнением первого порядка. Результаты опытов представлены в таблице 2, которая доказывает очевидность нашего предположения. 
Термическая инактивация протеиназы II «Протепсина» при рН 5,0

\begin{tabular}{|c|c|c|c|c|c|c|c|c|}
\hline \multirow{4}{*}{$\tau, \mathrm{ч}$} & \multicolumn{8}{|c|}{ Температура } \\
\hline & \multicolumn{4}{|c|}{$40^{\circ} \mathrm{C}$} & \multicolumn{4}{|c|}{$50^{\circ} \mathrm{C}$} \\
\hline & \multicolumn{2}{|c|}{ ПА } & \multicolumn{2}{|c|}{ MCA } & \multicolumn{2}{|c|}{ ПА } & \multicolumn{2}{|c|}{ MCA } \\
\hline & $\mathrm{E}$ & $\mathrm{K}^{*} 10^{3}, \mathrm{u}^{-1}$ & $\mathrm{E}$ & $\mathrm{K}^{*} 10^{3}, \mathrm{u}^{-1}$ & $\mathrm{E}$ & $\mathrm{K}^{*} 10^{3}, \mathrm{u}^{-1}$ & $\mathrm{E}$ & $\mathrm{K}^{*} 10^{3}, \mathrm{u}^{-1}$ \\
\hline 0 & 100 & - & 100 & - & 100 & - & 100 & - \\
\hline 12 & 100 & - & 100 & - & 65,1 & 37,0 & 63,2 & 38,1 \\
\hline 24 & 92,3 & 2,33 & 93,4 & 2,48 & 45,2 & 33,6 & 42,3 & 36,0 \\
\hline 48 & 87,8 & 2,54 & 88,0 & 2,54 & 16,8 & 37,7 & 18,1 & 36,3 \\
\hline 96 & 81,5 & 2,19 & 81,0 & 2,23 & 7,6 & 36,8 & 7,0 & 37,1 \\
\hline 120 & 77,2 & 2,36 & 78,3 & 2,23 & 6,7 & 35,7 & 6,5 & 37,7 \\
\hline 144 & 71,4 & 2,28 & 75,6 & 2,16 & 6,5 & 33,1 & 6,0 & 34,0 \\
\hline 168 & 68,2 & 2,30 & 66,3 & 2,50 & 5,9 & 34,1 & 5,9 & 34,1 \\
\hline 192 & 60,9 & 2,54 & 62,2 & 2,56 & 5,2 & 35,9 & 5,4 & 35,9 \\
\hline
\end{tabular}

Таким образом, препарат «Протепсин» прослеживает сходность физико-химических и биокаталитических свойств входящих в него ферментов с аналогами из растений, микроорганиз-

\section{ЛИТЕРАТУРА}

1 Frost, Sullivan Обзор рынка биотехнологий в России и оценка перспектив его развития // РВК. 2014. 70 c.

2 Пономарев В.Я. Оценка генотоксичности новых видов ферментированных мясопродуктов // Ученые записки Казанской государственной академии ветеренарной медицины им. Н.Э. Баумана. 2010. Т. 200. С. 168-172.

3 Melim Miguel A.S., Martins-Meyer T.S., da Costa Figueiredo E.V., Paulo Lobo B.W., Dellamora - Ortiz G.M. Enzymes in Bakery // Current and Future Trends. 2013. №1. P. 287-321.

4 Antipova L.V., Gorbunkov M.V., Storublevtsev S.A. The experience of enzyme preparation application in the processing of animal origin raw materials // Europen Journal of Natural History. 2015. №2. P. 42-43.

5 Сливкин А.И. и др. Изучение физикохимических и кинетических свойств комплексного ферментного биопрепарата // Вестник Воронежского государственного университета. Серия: Химия. Биология. Фармация. 2015. №2. C. $120-123$.

6 Лисицын А.Б. и др. Производство мясной продукции на основе биотехнологии: учеб. для вузов. М.: ВНИИМП, 2005. 369 с.

7 Келепин Т.В. Основы ферментативной кинетики. М.: Мир, 1990. 350 с. мов и животных, обеспечивает заданный диапазон активности и стабильности. Следует ожидать хорошие результаты и перспективность применения в технологии мясных и молочных продуктов.

\section{REFERENCES}

1 Frost, Sullivan The review of the market of biotechnologies in Russia and an assessment of prospects of its development. RVK, 2014. $70 \mathrm{p}$.

2. Ponomarev V.Ya. Evaluation of genotoxicity of new kinds of fermented meat products. Uchenye zapiski Kazanskoj gosudarstvennoj akademii veterenarnoj mediciny imeni Baumana. [Scientific notes of the Kazan state academy of veterinary medicine of N.E. Bauman], 2010, vol. 200, pp. 168-172. (In Russ.).

3 Melim Miguel A.S., Martins-Meyer T.S., da Costa Figueiredo E.V., Paulo Lobo B.W., Dellamora - Ortiz G.M. Enzymes in Bakery. Current and Future Trends, 2013, no. 1, pp. 287-321.

4 Antipova L.V., Gorbunkov M.V., Storublevtsev S.A. The experience of enzyme preparation application in the processing of animal origin raw materials. Europen Journal of Natural History, 2015, no. 2, pp. 42-43.

5 Slivkin A.I. et al. Studying of physical and chemical and kinetic properties of a complex fermental biological product. Vestnik Voronezhskogo gosudarstvennogo universiteta. Seriya. Himiya. Biologiya. Farmaciya [Messenger of the Voronezh state university. Series: Chemistry. Biology. Pharmacy], 2015, no. 2, pp. 120-123. (In Russ.).

6 Lisitsyn A.B. et al. Proizvodstvo myasnoi produktsii na osnove biotekhnologii [Production of meat production on the basis of Biotechnology]. Moscow, VNIIMP, 2005. 369 p. (In Russ.).

7 Kelepin T.V. Osnovy fermentativnoi kinetiki [Fundamentals of enzyme kinetics]. Moscow, Mir, 1990. 350 p. (In Russ.). 